\title{
Transcatheter aortic valve replacement in patients with severe mitral or tricuspid regurgitation at extreme risk for surgery
}

Stephen H. Little, MD, ${ }^{a}$ Jeffrey J. Popma, MD, ${ }^{b}$ Neal S. Kleiman, MD, ${ }^{a}$ G. Michael Deeb, MD, ${ }^{c}$ Thomas G. Gleason, MD, ${ }^{\mathrm{d}}$ Steven J. Yakubov, MD, ${ }^{\mathrm{e}}$ Stan Checuti, MD ${ }^{\mathrm{c}}$ Daniel O'Hair, MD, ${ }^{\mathrm{f}}$ Tanvir Bajwa, MD,${ }^{\mathrm{f}}$ Mubashir Mumtaz, MD, ${ }^{\mathrm{g}}$ Brijeshwar Maini, MD, ${ }^{\mathrm{g}, \mathrm{h}}$ Alan Hartman, MD, ${ }^{\mathrm{i}}$ Stanley Katz, MD, ${ }^{i}$ Newell Robinson, MD,${ }^{j}$ George Petrossian, MD, ${ }^{j}$ John Heiser, MD, ${ }^{k}$ William Merhi, MD, B. Jane Moore, MS, ${ }^{1}$ Shuzhen Li, PhD, ${ }^{1}$ David H. Adams, MD,${ }^{\mathrm{m}}$ and Michael J. Reardon, $\mathrm{MD}^{\mathrm{a}}$

\section{ABSTRACT}

Objectives: Patients with symptomatic severe aortic stenosis and severe mitral regurgitation or severe tricuspid regurgitation were excluded from the major transcatheter aortic valve replacement trials. We studied these 2 subgroups in patients at extreme risk for surgery in the prospective, nonrandomized, single-arm CoreValve US Expanded Use Study.

Methods: The primary end point was all-cause mortality or major stroke at 1 year. A favorable medical benefit was defined as a Kansas City Cardiomyopathy Questionnaire overall summary score greater than 45 at 6 months and greater than 60 at 1 year and with a less than 10-point decrease from baseline.

Results: There were 53 patients in each group. Baseline characteristics for the severe mitral regurgitation and severe tricuspid regurgitation cohorts were age $84.2 \pm 6.4$ years and $84.9 \pm 6.5$ years; male, $29(54.7 \%)$ and $22(41.5 \%)$, and mean Society of Thoracic Surgeons score $9.9 \% \pm 5.0 \%$ and $9.2 \% \pm 4.0 \%$, respectively. Improvement in valve regurgitation from baseline to 1 year occurred in $72.7 \%$ of the patients with severe mitral regurgitation and in $61.8 \%$ of patients with severe tricuspid regurgitation. A favorable medical benefit occurred in 31 of 47 patients $(66.0 \%)$ with severe mitral regurgitation and 33 of 47 patients $(70.2 \%)$ with severe tricuspid regurgitation at 6 months, and in 25 of 44 patients $(56.8 \%)$ with severe mitral regurgitation and 24 of 45 patients $(53.3 \%)$ with severe tricuspid regurgitation at 1 year. All-cause mortality or major stroke for the severe mitral regurgitation and severe tricuspid regurgitation cohorts were $11.3 \%$ and $3.8 \%$ at 30 days and $21.0 \%$ and $19.2 \%$ at 1 year, respectively. There were no major strokes in either group at 1 year.

Conclusions: Transcatheter aortic valve replacement in patients with severe mitral regurgitation or severe tricuspid regurgitation is reasonable and safe and leads to improvement in atrioventricular valve regurgitation. ( $\mathrm{J}$ Thorac Cardiovasc Surg 2018;155:1991-9)

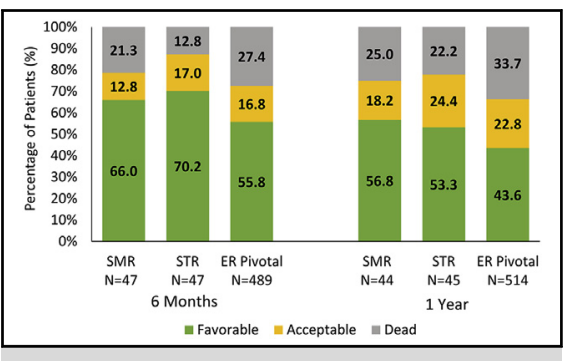

Health benefit for patients receiving TAVR with SMR or STR and patients in the Extreme Risk Trial.

\section{Central Message}

TAVR in patients with severe AS and severe mitral or tricuspid regurgitation is reasonable and safe, and leads to improvement in valve regurgitation and quality of life.

\section{Perspective}

Patients with severe AS and SMR or STR were excluded from major US TAVR trials because they met the indications for atrioventricular valve surgery by consensus and current guidelines. Yet, we showed that for inoperable patients with severe AS and SMR or STR, TAVR can be performed safely with a reasonable chance of improvements in regurgitation and quality of life.

See Editorial Commentary page 2000.

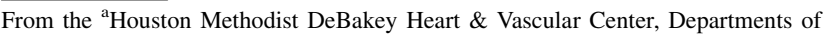
Cardiothoracic Surgery and Cardiology, Houston, Tex; ${ }^{\mathrm{b}}$ Interventional Cardiology, Beth Israel Deaconess Medical Center, Boston, Mass; ${ }^{\mathrm{c}}$ Departments of Cardiac Surgery and Interventional Cardiology, University of Michigan Hospitals, Ann Arbor, Mich; ${ }^{\mathrm{d}}$ Department of Cardiothoracic Surgery, University of Pittsburgh School of Medicine, Pittsburgh, Pa; ${ }^{\mathrm{e}}$ Interventional Cardiology, Riverside Methodist Hospital, Columbus, Ohio; ${ }^{\mathrm{f}}$ Departments of Cardiothoracic Surgery and Interventional Cardiology, St Luke's Medical Center, Aurora Health Care, Milwaukee, Wis; ${ }^{\mathrm{g}}$ Pinnacle Health Harrisburg Hospital, Harrisburg, Pa; ${ }^{\mathrm{h}}$ Department of Intervention Cardiology, Delray Medical Center, Delray Beach, Fla; ${ }^{\mathrm{i}}$ Departments of Cardiovascular Surgery and Interventional Cardiology, North Shore University Hospital, Manhasset, NY; ${ }^{\mathrm{j}}$ Departments of Cardiothoracic and Vascular Surgery and Interventional Cardiology, St Francis Hospital, Roslyn, NY; ${ }^{\mathrm{k}}$ Departments of Cardiothoracic Surgery and Interventional Cardiology, Spectrum Health Hospitals, Grand Rapids, Mich; ${ }^{1}$ Clinical Services and Statistical Services, Medtronic, Min-
}

neapolis, Minn; and ${ }^{\mathrm{m}}$ Department of Cardiovascular Surgery, Mount Sinai Health System, New York, NY.

Funded by Medtronic, Inc, Minneapolis, Minn

Clinicaltrials.gov Identifier: NCT01675440

Read at the 97th Annual Meeting of The American Association for Thoracic Surgery, Boston, Massachusetts, April 29-May 3, 2017.

Received for publication May 5, 2017; revisions received Oct 22, 2017; accepted for publication Nov 29, 2017; available ahead of print Feb 8, 2018.

Address for reprints: Michael J. Reardon, MD, Houston Methodist DeBakey Heart \& Vascular Center, 6550 Fannin, Suite 1401, Houston, TX 77030 (E-mail mreardon@houstonmethodist.org).

$0022-5223 / \$ 36.00$

Copyright (c) 2018 by The American Association for Thoracic Surgery

https://doi.org/10.1016/j.jtcvs.2017.11.108 


\section{Abbreviations and Acronyms \\ AS $=$ aortic stenosis \\ $\mathrm{ER} \quad=$ extreme risk \\ KCCQ-OSS $=$ Kansas City Cardiomyopathy \\ Questionnaire Overall Summary \\ Score \\ MR = mitral regurgitation \\ SAVR = surgical aortic valve replacement \\ SMR = severe mitral regurgitation \\ STR $=$ severe tricuspid regurgitation \\ TAVR $=$ transcatheter aortic valve replacement \\ TR $=$ tricuspid regurgitation}

Scanning this QR code will take you to the article title page. To view the AATS Annual Meeting Webcast, see the URL next to the webcast thumbnail.

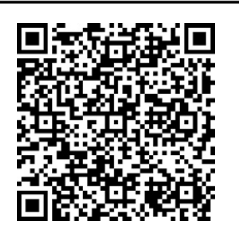

Aortic valve stenosis is a commonly acquired valve pathology that has led surgical aortic valve replacement (SAVR) to be the most common cardiac valve operation. ${ }^{1}$ Severe aortic stenosis (AS) is often associated with mitral regurgitation (MR) or tricuspid regurgitation (TR). If either of these are severe, consensus and current guidelines would support correction of the atrioventricular valve regurgitation at the time of SAVR. ${ }^{2}$

The introduction of transcatheter aortic valve replacement (TAVR) has led to rapid adoption of this technology for the treatment of symptomatic severe AS, supported by trials in nonoperative patients showing superior outcomes to medical therapy ${ }^{3,4}$ and randomized trials in high-risk patients showing noninferiority ${ }^{5}$ or superiority. ${ }^{6}$ Recently, 2 intermediate-risk trials showed TAVR to be noninferior to SAVR. ${ }^{7,8}$ Severe mitral regurgitation (SMR) and severe tricuspid regurgitation (STR) were protocol exclusions in these clinical trials. Little is known about outcomes in patients with symptomatic severe AS who are considered for TAVR but also have SMR or STR. The purpose of the CoreValve Expanded Use Study was to examine outcomes in patient subgroups that were excluded from the major TAVR trials, such as those with symptomatic severe AS who are at prohibitive risk for SAVR and have concomitant SMR or STR.

\section{MATERIALS AND METHODS \\ Study Design}

CoreValve US Expanded Use is a prospective, multicenter, nonrandomized study that evaluated the safety and efficacy of the CoreValve self- expanding transcatheter aortic valve (Medtronic, Minneapolis, Minn) in patient subgroups excluded from the CoreValve US Pivotal Extreme Risk Trial. ${ }^{49}$ SMR and STR are 2 such groups, and they make up the study cohorts for this report.

\section{Patients}

Eligible patients with severe, symptomatic, native AS and either STR or SMR were to have a 30-day predicted risk of surgical mortality of at least $50 \%$. Severe AS was defined as a mean gradient greater than $40 \mathrm{~mm} \mathrm{Hg}$ or jet velocity greater than $4.0 \mathrm{~m} / \mathrm{s}$ and an aortic valve area $0.8 \mathrm{~cm}^{2}$ or less. SMR was based on American College of Cardiology/American Heart Association guidelines on the qualitative and quantitative assessment. ${ }^{10}$ STR was based on the American Society of Echocardiography recommendations for 2-dimensional and Doppler echocardiography assessment. ${ }^{11}$ Valve regurgitation assessment was based on site-reported echocardiography performed within 45 days before assessment by the Screening Committee. Patient eligibility was confirmed by a Screening Committee comprising cardiac surgeons and interventional cardiologists. Each institutional review board approved the study protocol, and each patient provided a signed informed consent form.

\section{Procedures}

Implantation of the CoreValve system followed the same procedures as previously described. ${ }^{4}$ Four valve sizes were available in the Expanded Use Study: $23 \mathrm{~mm}, 26 \mathrm{~mm}, 29 \mathrm{~mm}$, and $31 \mathrm{~mm}$ for annular diameters from 18 to $29 \mathrm{~mm}$.

Patients were assessed at discharge and 1, 6, and 12 months postprocedure. Follow-up is planned for 5 years. The severity of tricuspid valve regurgitation was retrospectively evaluated in the CoreValve US Expanded Use Study. All available echocardiography reports were reviewed, and the severity of the tricuspid valve regurgitation documented. If a nonspecific grade was documented, such as moderate to severe, then an experienced echocardiographer (S.H.L.) reviewed the report and the echocardiographic imaging and determined the severity of the regurgitation on the basis of the current American Society of Echocardiography guideline criteria. ${ }^{11}$

\section{End Points}

The primary end point for this analysis was all-cause mortality or major stroke at 1 year. Quality of life as a measure of health benefit after TAVR at 6 months and 1 year was also evaluated. A favorable health benefit was defined as a Kansas City Cardiomyopathy Questionnaire overall summary score (KCCQ-OSS) greater than 45 at 6 months and greater than 60 at 1 year, and with less than a 10-point decrease from baseline. ${ }^{12}$

Site-reported echocardiography assessments through 1 year were summarized. Improvement in MR or TR, defined as at least a 1-grade change from baseline to discharge or 30 days (if discharge was not available) and from baseline to 1 year, was also evaluated.

\section{Statistical Methods}

The study cohorts include patients with SMR and patients with STR who underwent attempted implant. The 639 patients from the CoreValve US Pivotal Extreme-Risk Trial are included for context only, but no inferential statistical comparisons were made. Categoric variables are presented as counts and percentages, and continuous variables are presented as means \pm standard deviations. Event rates are reported as Kaplan-Meier estimates, and possible differences in mortality between groups were assessed with the log-rank test. Changes from baseline for KCCQ, mean gradient, and effective orifice area were assessed using the paired $t$ test. Improvement in valve regurgitation over time was defined as improvement of at least 1 grade from baseline to discharge or 1 month (using the earliest available echocardiographic assessment of regurgitation) and was compared using the Wilcoxon matched-pairs signed ranks test. A 2-sided alpha of 0.05 was used to determine significance. All statistical analyses 
TABLE 1. Baseline characteristics

\begin{tabular}{|c|c|c|c|}
\hline Characteristic & $\begin{array}{c}\text { Severe MR } \\
\quad \mathbf{N}=\mathbf{5 3}\end{array}$ & $\begin{array}{c}\text { Severe TR } \\
\quad \mathbf{N}=\mathbf{5 3}\end{array}$ & $\begin{array}{c}\text { CoreValve US pivotal ER } \\
\qquad \mathbf{N}=\mathbf{6 3 9}\end{array}$ \\
\hline Age (y) & $84.2 \pm 6.4$ & $84.9 \pm 6.5$ & $83.2 \pm 8.4$ \\
\hline $\operatorname{BSA}\left(\mathrm{m}^{2}\right)$ & $1.8 \pm 0.2$ & $1.8 \pm 0.2$ & $1.8 \pm 0.3$ \\
\hline Female & $29(54.7)$ & $22(41.5)$ & $302(47.3)$ \\
\hline STS PROM score $(\%)$ & $9.9 \pm 5.0$ & $9.2 \pm 4.0$ & $10.4 \pm 5.6$ \\
\hline \multicolumn{4}{|l|}{ NYHA } \\
\hline I & $0(0.0)$ & $0(0.0)$ & $0(0.0)$ \\
\hline II & $5(9.4)$ & $7(13.2)$ & $52(8.1)$ \\
\hline III & 39 (73.6) & 39 (73.6) & $411(64.3)$ \\
\hline IV & $9(17.0)$ & $7(13.2)$ & $176(27.5)$ \\
\hline Diabetes & $15(28.3)$ & $13(24.5)$ & $254(39.7)$ \\
\hline Serum creatinine $>2 \mathrm{mg} / \mathrm{dL}$ & $4(7.5)$ & $3(5.7)$ & $26(4.1)$ \\
\hline Chronic lung disease (COPD) & $34(64.2)$ & $22(41.5)$ & $396(62.0)$ \\
\hline Peripheral vascular disease & $23(43.4)$ & $26(49.1)$ & $263(41.4)$ \\
\hline Prior stroke & $9(17.0)$ & $5(9.4)$ & $88(13.8)$ \\
\hline Previous CABG & $22(41.5)$ & $19(35.8)$ & $254(39.7)$ \\
\hline Previous PCI & $18(34.0)$ & $17(32.1)$ & $229(35.8)$ \\
\hline Previous MI & $14(26.4)$ & $14(26.4)$ & $200(31.3)$ \\
\hline Atrial fibrillation/atrial flutter & $33(62.3)$ & $41(77.4)$ & $300(47.2)$ \\
\hline Porcelain aorta* & $1(1.9)$ & $3(5.8)$ & $36(5.7)$ \\
\hline Severely atherosclerotic aorta $\dagger$ & $6(11.3)$ & $4(7.7)$ & $109(17.1)$ \\
\hline Preexisting permanent pacemaker or defibrillator & $15(28.3)$ & $17(32.1)$ & $165(25.8)$ \\
\hline
\end{tabular}

Data presented as means \pm standard deviation or number (percentage) that reflect missing values. $M R$, Mitral regurgitation; $T R$, tricuspid regurgitation; $E R$, extreme risk; $B S A$, body surface area; STS PROM, Society of Thoracic Surgery Predicted Risk of Mortality; NYHA, New York Heart Association; COPD, chronic obstructive pulmonary disease; $C A B G$, coronary artery bypass grafting; $P C I$, percutaneous coronary intervention; $M I$, myocardial infarction. *As documented in medical history. †Based on screening multislice computed tomography.

were performed using Statistical Analysis Systems software, version 9.2 (SAS Institute, Inc, Cary, NC).

\section{RESULTS}

\section{Patients}

All patients were deemed extreme risk (ER) for SAVR by the local heart team; the determination was confirmed by a national screening committee. Patient clinical characteristics and demographics are shown in Table 1. The mean ages for the SMR, STR, and pivotal ER cohorts were $84.2 \pm 6.4$ years, $84.9 \pm 6.5$ years, and $83.2 \pm 8.4$ years, respectively, and the mean STS Predicted Risk of Mortality scores were $9.9 \% \pm 5.0 \%, 9.2 \% \pm 4.0 \%$, and $10.4 \% \pm 5.6 \%$, respectively. These patients had many frailties, disabilities, and comorbidities (Table 2).

TABLE 2. Comorbidities, disabilities, and frailties

\begin{tabular}{lccc}
\hline \multicolumn{1}{c}{ Assessment } & $\begin{array}{c}\text { Severe MR } \\
\mathbf{N = 5 3}\end{array}$ & $\begin{array}{c}\text { Severe TR } \\
\mathbf{N}=\mathbf{5 3}\end{array}$ & $\begin{array}{c}\text { CoreValve US pivotal ER } \\
\mathbf{N}=\mathbf{6 3 9}\end{array}$ \\
\hline Home oxygen & $11(20.8)$ & $13(24.5)$ & $212(33.2)$ \\
Charlson comorbidity score $\geq 5$ & $31(59.6)$ & $27(50.9)$ & $389(60.9)$ \\
Severe STS chronic lung disease & $12(22.6)$ & $6(11.3)$ & $174(27.2)$ \\
Assisted living & $9(17.0)$ & $3(5.7)$ & $159(24.9)$ \\
$\geq 2$ Katz activities of daily living deficits & $8(15.1)$ & $3(5.7)$ & $131(20.5)$ \\
Anemia requiring transfusion & $8(16.0)$ & $7(13.2)$ & $144(23.3)$ \\
Albumin $<3.3$ g/dL & $11(20.8)$ & $6(11.5)$ & $113(17.9)$ \\
5-m gait speed $>6 \mathrm{~s}$ & $30(73.2)$ & $45(91.8)$ & $381(83.6)$ \\
Falls in recent 6 mo & $8(15.1)$ & $10(18.9)$ & $118(18.5)$ \\
\hline
\end{tabular}

Data presented as number (percentage) that reflect missing values. $M R$, Mitral regurgitation; $T R$, tricuspid regurgitation; $E R$, extreme risk; STS, Society of Thoracic Surgeons. 
TABLE 3. Procedural outcomes

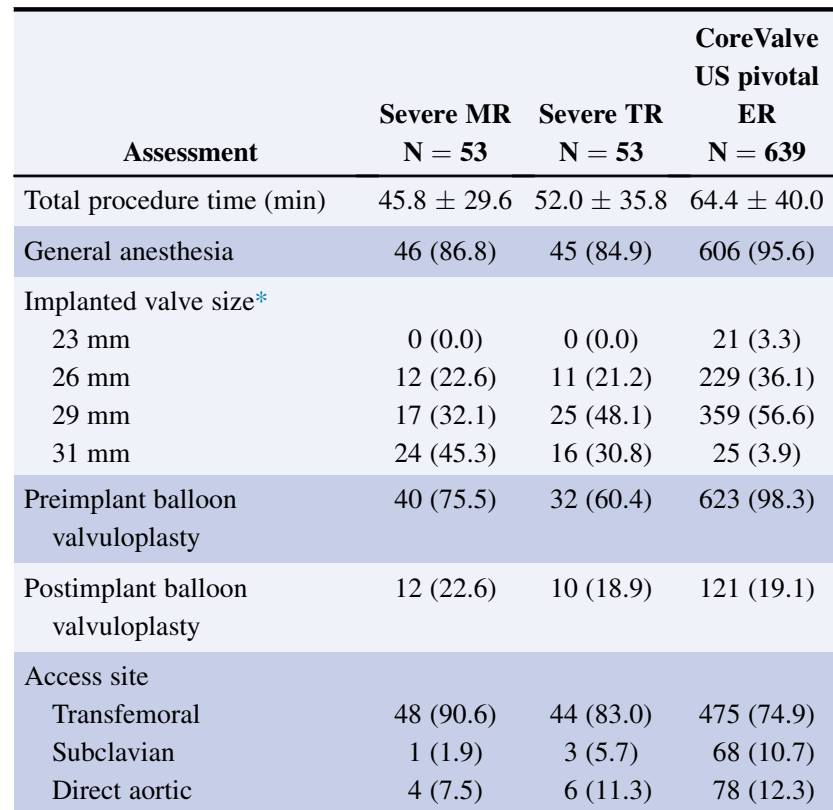

Data presented as means \pm standard deviation or number (percentage) that reflect missing values. $M R$, Mitral regurgitation; $T R$, tricuspid regurgitation; $E R$, extreme risk. *The 31-mm valve was added to the CoreValve US Pivotal ER Trial near the end of the enrollment period.

\section{Early Outcomes}

Procedural characteristics are shown in Table 3. The 30day all-cause mortality rates for the SMR, STR, and ER cohorts were $11.3 \%, 3.8 \%$, and $9.1 \%$, respectively (Table 4 ). There were no early major strokes, myocardial infarctions, coronary obstruction, or conversion to surgery in the SMR or STR cohorts.

\section{Primary Safety}

The 1-year all-cause mortality or major stroke rates were similar in the SMR $(21.0 \%)$ and STR groups $(19.2 \%)$ and less than in the ER group (29.1\%) (Figure 1). There were no major strokes in the SMR or STR groups.

\section{Valve Hemodynamics}

The mean aortic valve gradient was significantly reduced from $43.3 \pm 12.6 \mathrm{~mm} \mathrm{Hg}$ at baseline to $8.5 \pm 3.5 \mathrm{~mm} \mathrm{Hg}$ at discharge in the SMR group, and from $42.3 \pm 12.6 \mathrm{~mm} \mathrm{Hg}$ at baseline to $6.8 \pm 2.5 \mathrm{~mm} \mathrm{Hg}$ at discharge in the STR groups (both $P<.001$ ). Significant increases in the effective orifice area were also observed from baseline to discharge-from $0.62 \pm 0.17 \mathrm{~cm}^{2}$ to $1.71 \pm 0.45 \mathrm{~cm}^{2}$ for the SMR group and from $0.60 \pm 0.21 \mathrm{~cm}^{2}$ to $1.65 \pm 0.41 \mathrm{~cm}^{2}$ for the STR group (both $P<.001$ ). Paravalvular leak over time for the SMR and STR groups is shown in Figure 2.

Both SMR and STR improved significantly (all $P<.001$ ) after TAVR (Figures 3 and 4). At 1 year, $72.7 \%$ of patients with SMR showed improvement in MR and $61.8 \%$ of patients with STR showed improvement in TR compared with baseline. There were no differences in survival for patients who improved their SMR or STR from baseline to discharge or 1 month versus those who did not (Figures 3 and 4).

TABLE 4. Clinical outcomes at 30 days and 1 year

\begin{tabular}{|c|c|c|c|c|c|c|}
\hline & \multicolumn{3}{|c|}{$30 \mathrm{~d}$} & \multicolumn{3}{|c|}{$1 \mathbf{y}$} \\
\hline & $\begin{array}{c}\text { Severe MR } \\
\mathbf{N}=\mathbf{5 3}\end{array}$ & $\begin{array}{c}\text { Severe TR } \\
\mathbf{N}=\mathbf{5 3}\end{array}$ & $\begin{array}{c}\text { CoreValve US pivotal ER } \\
\qquad \mathbf{N}=639\end{array}$ & $\begin{array}{c}\text { Severe MR } \\
\quad \mathbf{N}=\mathbf{5 3}\end{array}$ & $\begin{array}{c}\text { Severe TR } \\
\mathbf{N}=\mathbf{5 3}\end{array}$ & $\begin{array}{c}\text { CoreValve US pivotal ER } \\
\qquad N=639\end{array}$ \\
\hline $\begin{array}{l}\text { All-cause mortality or major } \\
\text { stroke }\end{array}$ & $6(11.3)$ & $2(3.8)$ & $71(11.1)$ & $11(21.0)$ & $10(19.2)$ & $186(29.1)$ \\
\hline All-cause mortality & $6(11.3)$ & $2(3.8)$ & $58(9.1)$ & $11(21.0)$ & $10(19.2)$ & $173(27.1)$ \\
\hline Cardiovascular & $5(9.5)$ & $1(1.9)$ & $58(9.1)$ & $10(19.4)$ & $8(16.0)$ & $130(20.7)$ \\
\hline Myocardial infarction & $0(0.0)$ & $0(0.0)$ & $9(1.4)$ & $1(2.2)$ & $1(2.3)$ & $12(2.0)$ \\
\hline Major stroke & $0(0.0)$ & $0(0.0)$ & $22(3.5)$ & $0(0.0)$ & $0(0.0)$ & $32(5.4)$ \\
\hline Major vascular complication & $7(13.3)$ & $8(15.1)$ & $53(8.3)$ & $7(13.3)$ & $9(17.1)$ & $55(8.7)$ \\
\hline $\begin{array}{l}\text { Life-threatening or disabling } \\
\text { bleeding }\end{array}$ & $3(5.7)$ & $1(1.9)$ & 99 (15.6) & $6(12.4)$ & $5(11.3)$ & $128(20.7)$ \\
\hline Prosthetic valve thrombosis & $0(0.0)$ & $0(0.0)$ & $0(0.0)$ & $0(0.0)$ & $0(0.0)$ & $1(0.2)$ \\
\hline Prosthetic valve endocarditis & $0(0.0)$ & $0(0.0)$ & $1(0.2)$ & $0(0.0)$ & $0(0.0)$ & $7(1.4)$ \\
\hline $\begin{array}{l}\text { Valve embolization or } \\
\text { migration }\end{array}$ & $0(0.0)$ & $0(0.0)$ & $0(0.0)$ & $0(0.0)$ & $0(0.0)$ & $1(0.2)$ \\
\hline Conversion to open surgery & $0(0.0)$ & $0(0.0)$ & NA & $0(0.0)$ & $0(0.0)$ & NA \\
\hline $\begin{array}{l}\text { New permanent pacemaker } \\
\text { required }\end{array}$ & $13(24.9)$ & $8(15.1)$ & $128(20.4)$ & 15 (29.6) & $9(17.2)$ & $154(25.3)$ \\
\hline Coronary artery obstruction & $0(0.0)$ & $0(0.0)$ & NA & $0(0.0)$ & $0(0.0)$ & NA \\
\hline
\end{tabular}

Data presented as number of patients (Kaplan-Meier rates). $M R$, Mitral regurgitation; $T R$, tricuspid regurgitation; $E R$, extreme risk; $N A$, not available. 


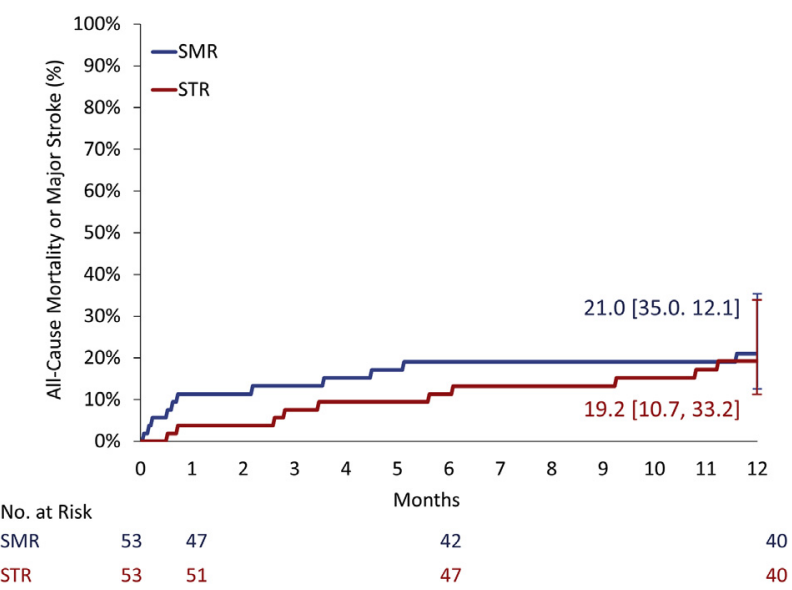

FIGURE 1. Kaplan-Meier 1-year all-cause mortality or major stroke. Allcause mortality or major stroke displayed by Kaplan-Meier analyses for patients with SMR and patients with STR at baseline, and for all patients in the CoreValve US Pivotal Extreme Risk Trial. Error bars represent $95 \%$ confidence intervals. SMR, Severe mitral regurgitation; STR, severe tricuspid regurgitation.

Quality of life. The improvement in KCCQ-OSS compared with baseline was significant (all $P<.001$ ) and at least 20 points for all 3 groups at each time point (Figure 5). A favorable medical benefit occurred in 31 of 47 patients $(66.0 \%)$ with SMR and 33 of 47 patients $(70.2 \%)$ with STR at 6 months, and in 25 of 44 patients $(56.8 \%)$ with SMR and 24 of 45 patients $(53.3 \%)$ with STR at 1 year. The proportion of patients with a favorable health benefit was similar for the SMR and STR patient cohorts and higher than seen in the ER patient cohort (Central Image).

\section{DISCUSSION}

The primary end point of all-cause mortality or major stroke for patients with symptomatic severe AS and SMR or STR at prohibitive risk for surgery undergoing
TAVR with the self-expanding valve was similar to TAVR in patients with prohibitive risk without SMR or STR. We saw improvement in both MR and TR, as well as gains in quality of life. More patients with SMR and STR had a favorable health benefit than patients without SMR or STR in the CoreValve US Pivotal Extreme Risk Trial.

The presence of MR or TR in patients with severe AS is not uncommon. Mild regurgitation is not generally addressed surgically at the time of SAVR, and controversy exists over the need to address moderate levels of regurgitation. ${ }^{13-15}$ For patients with severe MR or TR undergoing SAVR, there is consensus and guideline support for correction of the atrioventricular valve regurgitation at the time of SAVR. ${ }^{2}$ The availability of TAVR has allowed the treatment of symptomatic severe AS in patients who are not considered candidates for surgery. Patients with less than severe MR or TR have been included in the clinical trials. Outcomes in these studies have been divergent, with some showing an increase in mortality and some showing no effect on mortality. ${ }^{16-18}$ The presence of SMR or STR poses a challenge because these patients were excluded from the clinical trials used to approve TAVR, and the outcomes if left untreated are largely unknown. This trial was conducted to see if TAVR under these circumstances is reasonable based on survival and medical benefit.

The primary difference in patient recruitment in the CoreValve Expanded Use Study and the CoreValve US Pivotal Extreme Risk Trial was that SMR and STR were exclusion criteria of the latter. All groups were elderly (Table 1), and the clinical status (Table 2) revealed an ER group. There were no major strokes in the SMR or STR groups. All-cause mortality rates for SMR, STR, and the CoreValve US Pivotal ER Trial were $19.2 \%$, $21.0 \%$, and $29.1 \%$, respectively, indicating that survival after TAVR was not appreciably reduced by the presence of SMR or STR.
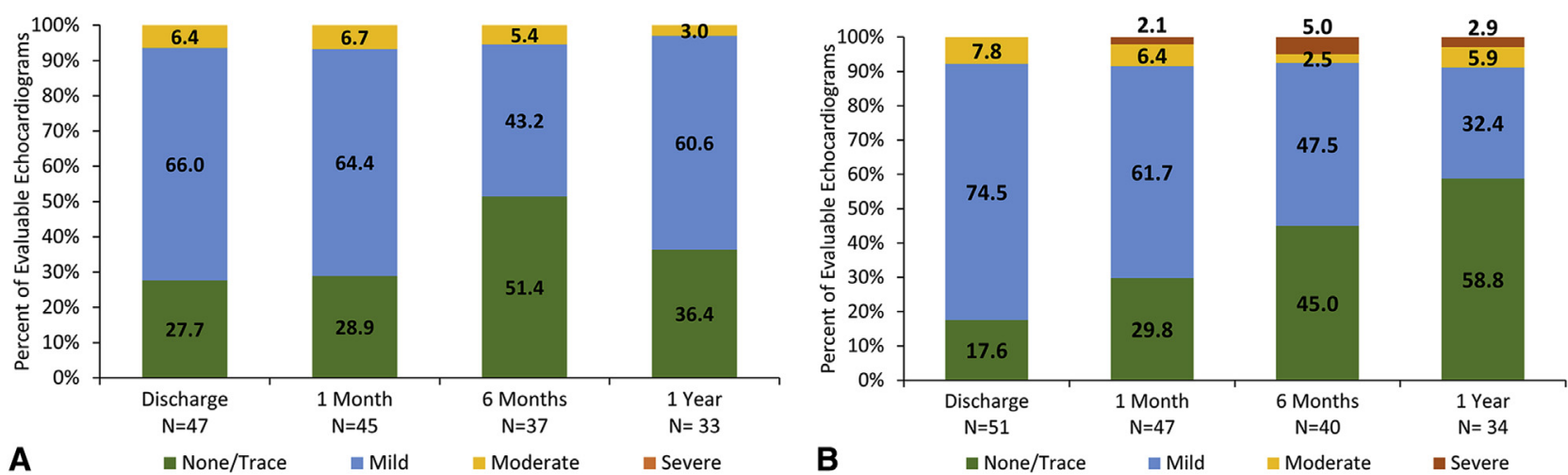

FIGURE 2. Paravalvular leak over time. Site-reported paravalvular leak over time for (A) patients with SMR at baseline and (B) patients with STR at baseline. 

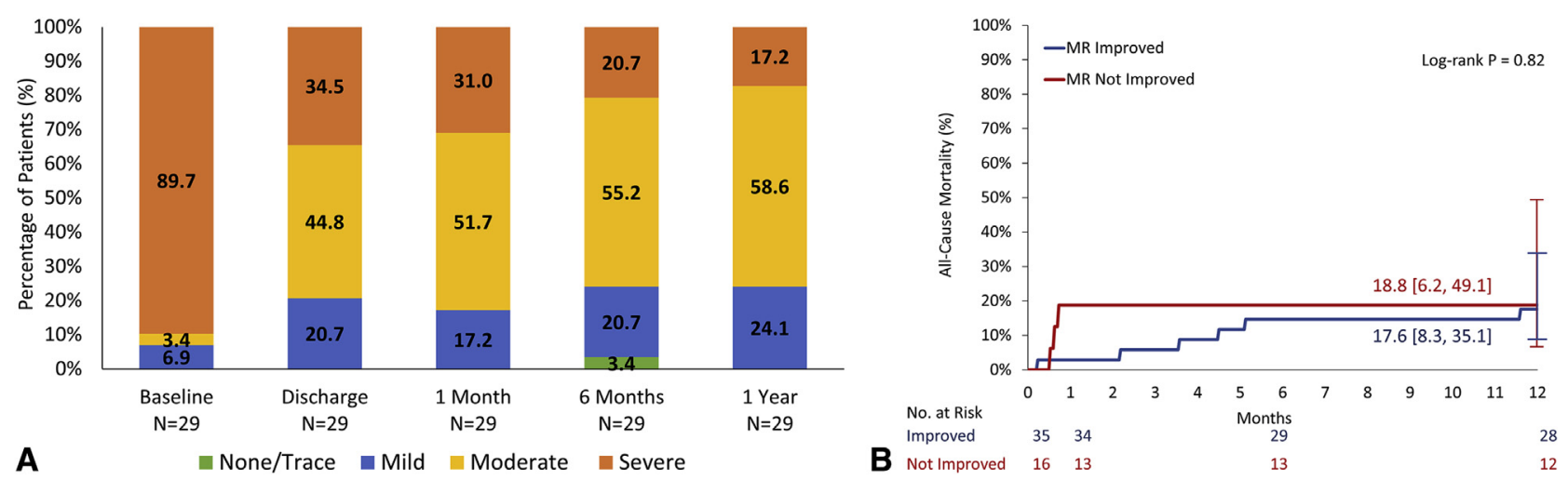

FIGURE 3. Changes in MR over time. A, MR for matched patients to 1 year. Changes from baseline to 1,6 , and 12 months were all significant $(P<.001)$. All patients had evidence of moderate SMR before TAVR. B, All-cause mortality to 1 year based on an improvement in MR by at least 1 grade between baseline and discharge (1 month used if discharge not available). Error bars represent $95 \%$ confidence intervals. MR, Mitral regurgitation.

MR and TR both improved significantly after TAVR. The improvement in MR continued to show improvement over the 1 year of the study, whereas the improvement in TR seen at 1 month tended to remain stable. There was no significant difference in mortality for those who improved and those who did not in either group, although those with STR who did not improve seemed to trend toward worse survival.

The KCCQ-OSS was used as a measure of quality of life. This instrument is a 100-point scale in which a 5-point increase is considered small, a 10-point increase is considered moderate, and a 20-point increase is considered a large improvement. ${ }^{19}$ The patients with SMR and STR had large improvements in quality of life compared with baseline at all time points (Figure 5). We observed a health benefit for both SMR and STR that compared favorably with the ER over all groups. For these nonsurgical patients who did not show appropriate improvement, the residual MR or TR can be treated by other available transcatheter options. ${ }^{20-22}$

\section{Study Limitations}

Our analyses have a few limitations. The CoreValve US Pivotal Extreme Risk Trial was not contemporaneous with the Expanded Use Study of SMR and STR. The classification of primary versus secondary MR was not collected for the SMR study cohort. These small study cohorts were further reduced by patient deaths and missing quality of life or echocardiographic data for some variables reported. All echocardiographic measures were site reported. Longer-term follow-up is warranted.

\section{CONCLUSIONS}

In patients at ER for SAVR who have symptomatic severe AS and SMR or STR, TAVR can be performed with acceptable survival, improvement of MR and TR severity, improvement in quality of life, and reasonable health benefit. Therefore, TAVR therapy is a reasonable treatment strategy for patients with symptomatic severe AS combined with SMR or STR.


FIGURE 4. Changes in TR over time. A, Tricuspid valve regurgitation for matched patients to 1 year. Changes from baseline to 1,6 , and 12 months were all significant $(P<.001)$. All patients had evidence of moderate STR before TAVR. B, All-cause mortality to 1 year for based on an improvement in TR by at least 1 grade between baseline and discharge (1 month used if discharges not available). Error bars represent $95 \%$ confidence intervals. TR, Tricuspid regurgitation. 


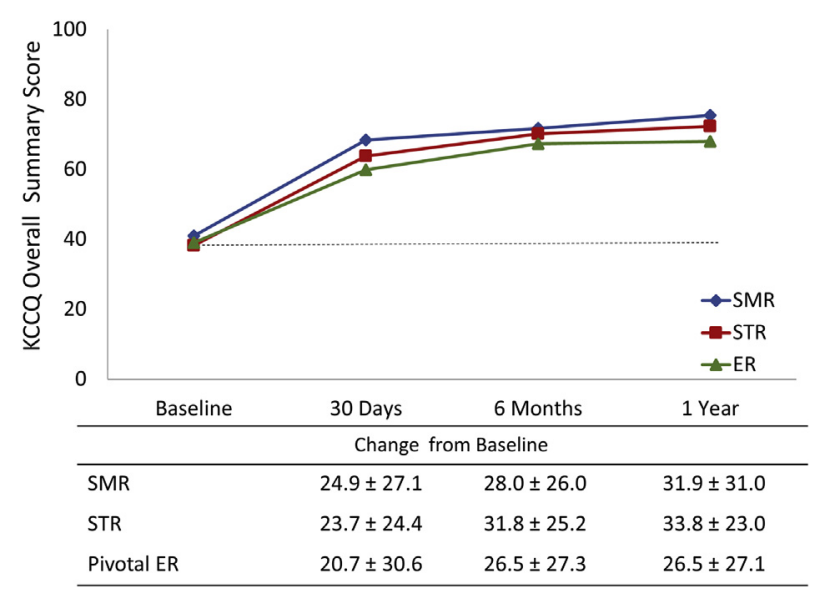

FIGURE 5. Kansas City Cardiomyopathy Questionnaire Quality of Life Assessments. The KCCQ-OSS for the SMR, STR, and ER pivotal cohorts over time. The dashed line represents an average of the 3 groups at baseline. The comparisons of mean overall summary scores between baseline and each follow-up for all 3 groups were statistically significant $(P<.001)$. KCCQ, Kansas City Cardiomyopathy Questionnaire; $S M R$, severe mitral regurgitation; $S T R$, severe tricuspid regurgitation; $E R$, extreme risk.

\section{Webcast}

You can watch a Webcast of this AATS meeting presentation by going to: https://aats.blob.core.windows.net/ media/17AM/2017-05-02/BallroomABC/05-02-17_Ballroom ABC_1402_Reardon.mp4.

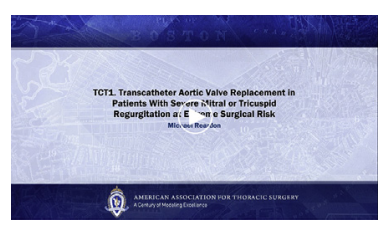

\section{Conflict of Interest Statement}

S.H.L. has served on the speaker's bureau for St Jude Medical and has received grant support from Abbott Vascular and institutional support from Medtronic. J.J.P. reports grants to his institution from Medtronic and Boston Scientific, consultant fees from Direct Flow, and fees for serving on a medical advisory board from Boston Scientific. N.S.K. reports personal fees from Medtronic during the conduct of the study. G.M.D. is a clinical trial investigator for Medtronic and a research investigator for Gore Medical and receives consulting fees paid to his institution from Medtronic, Terumo, and Edwards Lifesciences. T.G.G. receives institutional grant support from Medtronic but receives no personal remunerations. S.J.Y. reports grant support, personal fees, and other support from Medtronic during the conduct of the study and grant support from Boston Scientific outside the submitted work. S.C. reports grants and fees for proctoring and consulting from Medtronic. D.O. has received grants from and served as a proctor for Medtronic, and received grant support from Edwards Lifesciences. T.B. has served as a proctor for Medtronic. M.M. reports personal fees from Medtronic during the conduct of the study, personal fees from Abbott, Edwards Lifesciences, and AtriCure outside the submitted work, serving as Chairman of Clinical Events Committee for Millipede, Inc, and serving as a member of the Clinical Events Committee for Abiomed. B.M. has served as speaker and a proctor, and has received institutional research grants from Medtronic, Boston Scientific, Abbott Vascular, and Direct Flow Medical. A.H., S.K. N.R., G.P., J.H., and W.M. report no conflicts. B.J.M. and S.L. are employees and shareholders of Medtronic, plc. D.H.A. reports other support from Medtronic during the conduct of the study, other support from NeoChord and Medtronic outside the submitted work, and patent royalties from Edwards Lifesciences (US9526615 B2 and US9011529 B2) and Medtronic (US8764821 B2). M.J.R. reports consulting fees paid to his institution from Medtronic.

The authors thank Julie Rapp, MBA, for overall study management, and Maggie Anderson, BS, for assistance in obtaining the echocardiographic images and reports for review. Both are employees and shareholders of Medtronic, plc.

\section{References}

1. Iung B, Vahanian A. Epidemiology of valvular heart disease in the adult. Nat Rev Cardiol. 2011;8:162-72.

2. Nishimura RA, Otto CM, Bonow RO, Carabello BA, Erwin JP III, Fleisher LA, et al. 2017 AHA/ACC focused update of the 2014 AHA/ACC guideline for the management of patients with valvular heart disease: a report of the American College of Cardiology/American Heart Association task force on clinical practice guidelines. J Am Coll Cardiol. 2017;70:252-89.

3. Leon MB, Smith CR, Mack M, Miller DC, Moses JW, Svensson LG, et al. Transcatheter aortic-valve implantation for aortic stenosis in patients who cannot undergo surgery. N Engl J Med. 2010;363:1597-607.

4. Popma JJ, Adams DH, Reardon MJ, Yakubov SJ, Kleiman NS, Heimansohn D, et al. Transcatheter aortic valve replacement using a self-expanding bioprosthesis in patients with severe aortic stenosis at extreme risk for surgery. J Am Coll Cardiol. 2014;63:1972-81.

5. Smith CR, Leon MB, Mack MJ, Miller DC, Moses JW, Svensson LG, et al. Transcatheter versus surgical aortic-valve replacement in high-risk patients. $N$ Engl J Med. 2011;364:2187-98.

6. Adams DH, Popma JJ, Reardon MJ, Yakubov SJ, Coselli JS, Deeb GM, et al. Transcatheter aortic-valve replacement with a self-expanding prosthesis. $N$ Engl J Med. 2014;371:1790-8.

7. Leon MB, Smith CR, Mack MJ, Makkar RR, Svensson LG, Kodali SK, et al. Transcatheter or surgical aortic-valve replacement in intermediate-risk patients. N Engl J Med. 2016;374:1609-20.

8. Reardon MJ, Van Mieghem NM, Popma JJ, Kleiman NS, Sondergaard L, Mumtaz M, et al. Surgical or transcatheter aortic-valve replacement in intermediate-risk patients. $N$ Engl J Med. 2017 [Epub ahead of print].

9. Reardon MJ, Adams DH, Coselli JS, Deeb GM, Kleiman NS, Chetcuti S, et al. Self-expanding transcatheter aortic valve replacement using alternative access sites in symptomatic patients with severe aortic stenosis deemed extreme risk of surgery. J Thorac Cardiovasc Surg. 2014;148:2869-76. e1-7.

10. Bonow RO, Carabello BA, Chatterjee K, de Leon AC Jr, Faxon DP, Freed MD et al. 2008 focused update incorporated into the ACC/AHA 2006 guidelines for the management of patients with valvular heart disease: a report of the American College of Cardiology/American Heart Association task force on practice guidelines (writing committee to revise the 1998 guidelines for the management of patients with valvular heart disease): endorsed by the society of cardiovascular anesthesiologists, society for cardiovascular angiography and interventions, and society of thoracic surgeons. Circulation. 2008;118:e523-661. 
11. Zoghbi WA, Enriquez-Sarano M, Foster E, Grayburn PA, Kraft CD, Levine RA, et al. Recommendations for evaluation of the severity of native valvular regurgitation with two-dimensional and Doppler echocardiography. J Am Soc Echocardiogr. 2003;16:777-802.

12. Arnold SV, Reynolds MR, Wang K, Magnuson EA, Baron SJ, Chinnakondepalli KM, et al. Health status after transcatheter or surgical aortic valve replacement in patients with severe aortic stenosis at increased surgical risk: results from the CoreValve US pivotal trial. JACC Cardiovasc Interv. 2015;8:1207-17.

13. Alghamdi AA, Elmistekawy EM, Singh SK, Latter DA. Is concomitant surgery for moderate functional mitral regurgitation indicated during aortic valve replacement for aortic stenosis? A systematic review and evidence-based recommendations. J Card Surg. 2010;25:182-7.

14. Chikwe J, Itagaki S, Anyanwu A, Adams DH. Impact of concomitant tricuspid annuloplasty on tricuspid regurgitation, right ventricular function, and pulmonary artery hypertension after repair of mitral valve prolapse. J Am Coll Cardiol. 2015;65:1931-8.

15. Kowalowka AR, Onyszczuk M, Wanha W, Deja MA. Do we have to operate on moderate functional mitral regurgitation during aortic valve replacement for aortic stenosis? Interact Cardiovasc Thorac Surg. 2016;23:806-9.

16. Bedogni F, Latib A, De Marco F, Agnifili M, Oreglia J, Pizzocri S, et al. Interplay between mitral regurgitation and transcatheter aortic valve replacement with the CoreValve revalving system: a multicenter registry. Circulation. 2013;128:2145-53.

17. Rodes-Cabau J, Dumont E, Doyle D, Lemieux J. Transcatheter valve-in-valve implantation for the treatment of stentless aortic valve dysfunction. $J$ Thorac Cardiovasc Surg. 2010;140:246-8.

18. Toggweiler S, Boone RH, Rodes-Cabau J, Humphries KH, Lee M, NobelaFranco L, et al. Transcatheter aortic valve replacement: outcomes of patients with moderate or severe mitral regurgitation. J Am Coll Cardiol. 2012;59:2068-74.

19. Spertus J, Peterson E, Conard MW, Heidenreich PA, Krumholz HM, Jones P, et al. Monitoring clinical changes in patients with heart failure: a comparison of methods. Am Heart J. 2005;150:707-15.

20. Cortes C, Amat-Santos IJ, Nombela-Franco L, Munoz-Garcia AJ, GutierrezIbanes E, De La Torre Hernandez JM, et al. Mitral regurgitation after transcatheter aortic valve replacement: prognosis, imaging predictors, and potential management. JACC Cardiovasc Interv. 2016;9:1603-14.

21. Nickenig G, Kowalski M, Hausleiter J, Braun D, Schofer J, Yzeiraj E, et al. Transcatheter treatment of severe tricuspid regurgitation with the edge-to-edge: Mitraclip technique. Circulation. 2017;135:1802-14.

22. Rudolph V, Schirmer J, Franzen O, Schluter M, Seiffert M, Treede H, et al. Bivalvular transcatheter treatment of high-surgical-risk patients with coexisting severe aortic stenosis and significant mitral regurgitation. Int J Cardiol. 2013;167:716-20.

Key Words: aortic stenosis, transcatheter aortic valve replacement, mitral valve regurgitation, tricuspid valve regurgitation

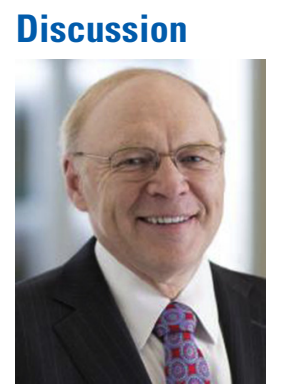

Dr L. Svensson (Cleveland, Ohio). That's a nice presentation of the selfexpanding balloons and mitral valve regurgitation. In the PARTNER trial, we have done similar analyses. Obviously in the trials there weren't supposed to be patients with severe MR, but there were patients with severe 3 grade MR. What was interesting, because we compared the patients who had surgical procedures with the patients who had TAVR, the recovery was better in the patients who had TAVR and greater. Also, as we know just from regular aortic valve replacements (AVRs), mitral valve regurgitation also recovered, but TAVR had a better result.

The other thing that we recently looked at, and Paul Cremer, MD, one of our young staff from Cleveland Clinic
Cardiovascular Medicine Section of Imaging, did the study, and was looking at TR and found surgery was associated with a twice higher risk of creating TR with an isolated AVR versus TAVR. One can speculate that is due to poor right side protection. Then on top of that, the patients after TAVR who had TR did slightly better than the patients who had AVR and had tricuspid valve regurgitation afterward. So there appears to be a benefit from that point of view for TAVR also.

I have 2 questions for you. One is, why do you think TAVR has a better recovery as far as MR over time? Is it because with surgery we may have some septal dysfunction? Is it because of the gradients with TAVR? Is this the penalty that of cardioplegia?

The second question I have for you is, traditionally with cardiac surgery if we see $3+\mathrm{MR}$, we will tend to repair that, and in these higher-risk patients or intermediate-risk patients, is it now reasonable to say that you can have a TAVR, we are not going to treat your mitral valve, it will probably recover, and is that sufficient? This gets into the broader question of not only mitral valve disease or tricuspid valve disease that is left behind with TAVR but also the whole issue I am seeing more of with our teams is that patients with coronary artery disease are also getting percutaneous coronary intervention. The reasoning is the patient does not have angina, it's a $70 \%$ lesion, we can always stent it later, and the lesion is left behind. I think ultimately the penalty is going to be that we might see at 10 years a higher mortality rate in those patients who don't get fully treated for MR, TR, or coronary artery disease.

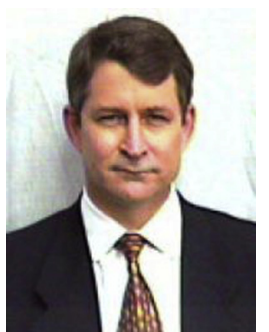

Dr Reardon. Well, you may have to help me remember the first one, Lars, because I am older than you, but I think it was, why does TAVR with MR get better more often than with surgery, and I think that is because we see 2 things after surgery that are probably related to cardioplegia. One is we see a decrease in the left ventricle stroke volume and we see right ventricular dysfunction, and those are 2 relatively consistent findings. I think this decrease in left ventricle stroke volume, which may even be related to right ventricle dysfunction, may affect your MR. But it's likely one of these things that's really hard to prove. And the second question was?

Dr Svensson. In the patient with, let's say, 3+ MR and the option is TAVR versus AVR, and with AVR the surgeon may consider doing the aortic valve and mitral valve, is it reasonable now to say, okay, we can just do the TAVR and ignore the mitral valve regurgitation of $3+$. If it doesn't work, we're going to put mitral clips onto your mitral valve later.

Dr Reardon. We all know that MR is a bad thing to have, and none of us would choose to have it if we had the choice. We also know that we decide whether or not you need TAVR first. If you need surgery, then the question is, how much risk do you add fixing it, and you really don't add that much risk, 
so we would fix it. In those people who are borderline, I do think that if you decide to perform TAVR, to me it's a combination of age and risk. In this trial, these people were almost 85 years old. When you're 85 years old, I'm operating on you to make you feel better, not to live longer, and these people felt better. If you were 70 years old, this would be a whole different ball game, because you may live 20 years. The people in this study are not going to live 20 years.

So I think the first decision is, are they really a TAVR candidate? If they are not a TAVR candidate, then you probably should be fixing them and fixing the aortic and mitral valves also, assuming it is significant MR.

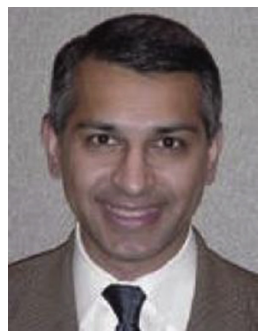

Dr V. Thourani (Atlanta, Ga). One of the questions from the text here is that do you have the mechanism of the $\mathrm{MR}$, that is, is it functional mitral valve regurgitation (FMR) or is it primary, and if it is, FMR commonly seems to get better whereas degenerative $\mathrm{P} 2$ prolapse won't get better after you perform AS surgery. So your thoughts on that.
Dr Reardon. I don't have those exact numbers, but of course that's a question we asked ourselves. When we set up this trial, we did not really look at that, because these were all nonoperative patients. But I can tell you from having gone through the trial, it's about three quarters FMR and one quarter primary MR. If my friend David Adams were here, not FMR but secondary MR. Three quarters were secondary MR, and one quarter were primary MR. I can't tell you the differences in the improvement. The way we did this, we didn't have an echo core lab, and so we'd have to gather all the echos, and we're already talking about doing that.

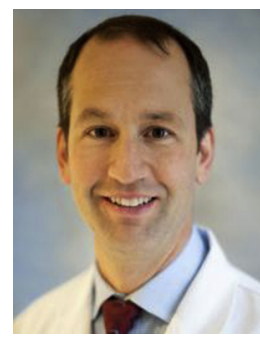

Dr M. Borger (Leipzig, Germany). But certainly if there is primary MR, we would sort of trend toward surgery or possibly in the future a MitraClip (Abbott Vascular, Abbott Park, Ill) or a transapical neochord down the road.

Dr Reardon. Correct, if there were surgical candidates, but all of these patients had been denied as surgical candidates.

Readers who found these articles interesting may also like to read the following papers found in recent and future issues of our sister publications, Seminars in Thoracic and Cardiovascular Surgery and Operative Techniques in Thoracic and Cardiovascular Surgery!

\section{Adult: Aortic Valve}

ORIGINAL SUBMISSION: Best Medical Treatment and Selective Stent-Graft Repair for Acute Type B Aortic Intramural Hematoma. Gabriele Piffaretti. Semin Thoracic Surg 2017: In press.

ORIGINAL SUBMISSION: Fluctuations in Spinal Cord Perfusion Pressure: a Harbinger of Delayed Paraplegia after Thoracoabdominal Aortic Repair. Harleen K. Sandhu. Semin Thoracic Surg 2017: 451-459.

Editorial Commentary: Keep Alert Eyes on Delayed Paraplegia. Kenji Minatoya. Semin Thoracic Surg 2017: 460-461.

Editorial Commentary: Problem Delayed Does Not Mean Solution Denied. Joseph S. Coselli. Semin Thoracic Surg 2017: 462-463

ORIGINAL SUBMISSION: Awake Thoracic Endovascular Aneurysm Repair for Aortic Rupture: A Case Series. Jessica Forcillo. Semin Thoracic Surg 2017: In press.

Editorial Commentary: Awake TEVAR for Ruptured Thoracic Aneurysms: Less is More? Akiko Tanaka. Semin Thoracic Surg 2017: In press.

ORIGINAL SUBMISSION: Impact of Discordant Views in the Management of Descending Thoracic Aortic Aneurysm. Peter Chiu. Semin Thoracic Surg 2017: 283-291.

Editorial Commentary: Surgery Is in the Eye of the Beholder. Anthony L. Estrera. Semin Thoracic Surg 2017: 292-293. 